\title{
Theoretical and Practical Challenges of Integrating Ecosystem Data
}

\author{
M. Hauhs, B. Trancón y. Widemann, and O. Archner \\ Ecological Modelling, BayCEER \\ (Bayreuth Center of Ecology and Environmental Research) \\ University of Bayreuth \\ Bayreuth, Germany \\ Michael.Hauhs@uni-bayreuth.de
}

\begin{abstract}
The challenges of data integration in the field of ecological and environmental research are exemplified by the widespread mixture of time series and maps. Typically ecosystem data sets originate from interdisciplinary studies organised around pragmatic, small scale or shortterm interests. Integration of such data, e.g. in geographic information systems or time series analysis has often been based on ad hoc solutions. The theoretical basis of the field has remained largely unsolved.

Here, we propose a categorical basis for the task of organising and integrating ecosystem data. We focus on time series (data streams) and on maps (spatial configurations of objects) as the two pure limiting cases illustrating typical data evaluation tasks. The core idea of our approach is to use the duality between algebra and coalgebra as the mathematical basis for representing and relating these two data types. This results in two dual modelling paradigms that relate the formal basis to testable models and experiments in different ways.

The application of our approach to existing studies of ecosystem data provides a systematic classification of the underlying concepts (see Fig. 1). The four cases result from the algebra/coalgebra duality and from the independent logical distinction between induction and deduction. Deduction is meant in the sense that time-variable aspects of a system follow from a priority of objects. Induction, conversely, is meant in the sense that classification and control of objects of a system follow from a priority of behavior. We claim that such a classification helps to explain current difficulties and indicates new potential in ecosystem data integration.
\end{abstract}

\begin{tabular}{|l|l|l|}
\hline $\begin{array}{l}\text { Notions of } \\
\text { Ecosystems }\end{array}$ & Deduction from Objects & Induction from Behavior \\
\hline $\begin{array}{l}\text { Non-reactive Systems } \\
\text { as Algebras }\end{array}$ & $\begin{array}{l}\text { Complex aggregates } \\
\text { (species, populations, ... })\end{array}$ & $\begin{array}{l}\text { Landscape functions } \\
\text { hydrological runoff, ... ) }\end{array}$ \\
\hline $\begin{array}{l}\text { Reactive Systems } \\
\text { as Coalgebras }\end{array}$ & $\begin{array}{l}\text { Carrier of values } \\
\text { (endangered species, ... .) }\end{array}$ & $\begin{array}{l}\text { Perpetuated service } \\
\text { (sustainable utilisation) }\end{array}$ \\
\hline
\end{tabular}

Fig. 1. Typical notions of ecosystems in science, management and politics 